\title{
Generation and development of the region cluster environment in the agro-industrial complex economy of the Rostov region
}

\author{
Svetlana Ugrimova ${ }^{1, *}$, Natalya Andreeva ${ }^{2}$ and Tatyana Tuchkanen ${ }^{1}$ \\ ${ }^{1}$ Don State Technical University, 1, pl. Gagarina, 344002, Rostov-on-Don, Russia \\ ${ }^{2}$ Rostov State University of Economics (RSUE), 69, str. Bolshaya Sadovaya, 344002, Rostov-on-Don, \\ Russia
}

\begin{abstract}
The issues concerning the study of topical problems of generation and development of the region cluster environment in the agroindustrial complex economy of the Rostov region in current economic conditions are considered in the paper. On the basis of the study, it is proved that the development of a region cluster environment in the agricultural sector can be achieved by the use of the more specific innovation policy in the agro-industrial complex upon the availability of the response strategy for given problems solution integrating structural and product policies.
\end{abstract}

\section{Introduction}

The importance of the Region Cluster Environment (RCE) generation for the growth of the agricultural sector economic indicators based on the innovation clusters development in various regions of the Russian Federation is conditioned by the need of its efficient economic development. The necessary precondition for the generation and development of RCE in the agro-industrial complex includes the economic indices of the gross regional product and the dynamic development of the agricultural sector.

The agro-industrial complex of the modern Russian economy is a rather comprehensive business structure that is essential to the sector development, since it influences the issues of the state sustained development and food safety provision. Innovative processes in the form of managed integration of self-dependent agricultural enterprises and other active participants along with collaboration in the field of functional market niche seem to be the necessary tools of the development of any sector of the country's economy, considering the direct impact on improvement of the products, goods or services quality. In such a case the category "innovation" should be considered as a novelty, new or improved product, or technology obtained as a result of the innovation process.

\footnotetext{
*Corresponding author: s.ugrimova@yandex.ru
} 


\section{Materials and methods}

The positive trends of the output of agricultural products produced and exported in the Rostov region represent the competitive abilities of the region agricultural factories. However, in the face of the low level of the region agricultural production fixed investments, decrease of this competitiveness is presumable in the future. Thus, the Rostov region in terms of the investment share in the agro-industrial complex lags far behind the share of agricultural output in the national volume (Table 1), which may cause the loss of the region leading positions on a federal scale.

Table 1. The changes of the highlight figures of the Rostov region agriculture development in 20122018.

\begin{tabular}{|c|c|c|c|c|c|c|c|}
\hline Parameter & 2012 & 2013 & 2014 & 2015 & 2016 & 2017 & 2018 \\
\hline 1 & 2 & 3 & 4 & 5 & 6 & 7 & 8 \\
\hline \multicolumn{8}{|c|}{$\begin{array}{l}\text { Agricultural products } \\
\text { Il categories: at effectiv }\end{array}$} \\
\hline Rostov region $^{1}$ & 154.7 & 161.3 & 172.5 & 219.0 & 252.8 & 254.4 & 255.1 \\
\hline Russian Federation ${ }^{2}$ & 3339.2 & 3687.1 & 4319.1 & 5165.7 & 5112.3 & 5109.5 & 5348.8 \\
\hline $\begin{array}{l}\text { The share of Rostov } \\
\text { region index in } \\
\text { Russian Federation } \\
\text { index (percent) }\end{array}$ & 4.6 & 4.4 & 4.0 & 4.2 & 4.9 & 5.0 & 4.8 \\
\hline \multicolumn{8}{|c|}{$\begin{array}{l}\text { Fixed investments (excluding small businesses) } \\
\text { (at effective prices) (billions of rubles) }\end{array}$} \\
\hline Rostov region $^{1}$ & 6.0 & 6.4 & 7.5 & 14.2 & 11.8 & 9.9 & 12.6 \\
\hline Russian Federation ${ }^{2}$ & 488.6 & 530.9 & 524.3 & 518.8 & 623.4 & 705.5 & 777.0 \\
\hline $\begin{array}{l}\text { The share of Rostov } \\
\text { region index in } \\
\text { Russian Federation } \\
\text { index (percent) }\end{array}$ & 1.2 & 1.2 & 1.4 & 2.7 & 1.9 & 1.4 & 1.6 \\
\hline
\end{tabular}

Where: ${ }^{1}$ Statistical yearbook Rostov region by numbers in 2018 and Statistical yearbook Rostov region by numbers in 2016 - https://rostov.gks.ru/folder/30195, ${ }^{2}$ Russian statistical yearbook 2017-2019 https://www.gks.ru/folder/210/document/12994.

Aside from the evaluation of the agricultural output and the investment climate of the region, its cluster potential is also measured by the level of the cross-border activity of enterprises forming the Rostov region agro-industrial complex (Figure 1) (https://www.exportcenter.ru/international_markets/regions_export/). 


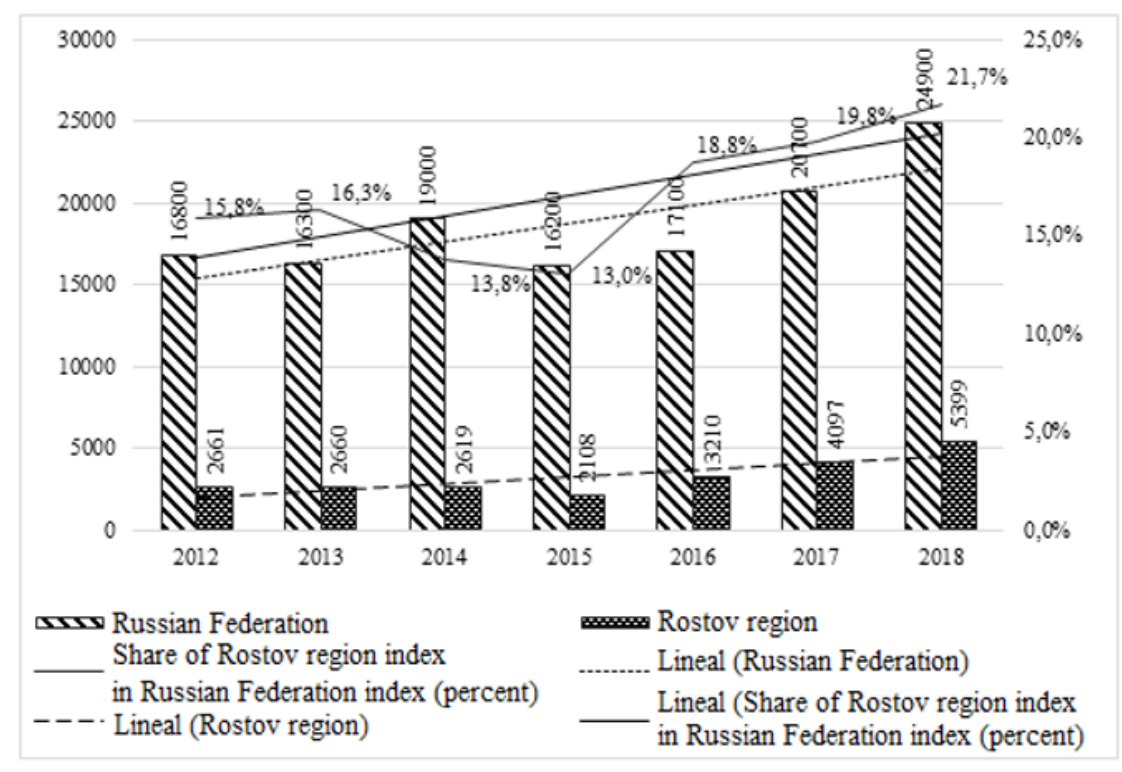

Fig. 1. Export of the food products and agricultural raw material (except textile) in the Rostov region in 2012-2018 (US Dollars million).

The diagram of the agricultural products export in the last seven years as shown in Figure 1 highlights that business-enabling environment is developed in the Rostov region for clustering processes in the agricultural sector.

Under the conditions of the complicated macroeconomic environment for the Russian Federation, sanction restrictions set by the European Union, the United States and Canada for the past half-decade, some problems of shortages occasionally occur in the distribution of various goods and services, including products of advanced technologies in the agrarian business. As follows from the updated standard macroeconomic forecast of the Analytic Credit Rating Agency (ACRA) for 2019-2023 the Russian economy growth is expected to decelerate to $0.9 \%$ in 2019 and to $0.8 \%$ in 2020 . According to the previous forecast, the GDP growth was estimated at $1.4 \%$ in 2019 and $1.5 \%$ in 2020 . As can be seen from the above, the economists made a worse forecast for the Russian economy growth despite the fact that the estimated probability of the new economic sanctions rollout against Russia had changed the value from "high" to "average".

Thus, in the current crisis conditions the key focus of enhancement, competitiveness and innovation potential improvement of the agricultural enterprises in the Rostov region is the development of region clusters.

\section{Discussion}

The role of agricultural policy in the economy of the agro-industrial complex should include not only the control of the food provision and stock forming processes, but also the support of national agricultural producers, that can be achieved by generation and development of the region cluster environment as an innovative model in the management of the territory's agrarian business. The scientists of the research and educational establishments throughout the world study the issues of cooperation, integration and clusters development in the agricultural sector. The current economic science research sources offer various clusters classifications. It should be noted, for instance, that some scientists argue that it is with the use of innovative technologies that clusters based on 
knowledge can be identified. As usual, they belong to the sectors with the high level of research, commonly formed in the process of active studies of the agencies in the region or state [1]. So, the authors M. Franco and L. Esteves use the term "cluster" conceptually as a synonym for industrial agglomeration [2]. The interpretations of the "cluster" concept are enriched by its current understanding in the papers of a number of scientists. Clusters can take on a variety of forms, depending on the fields of specialty. In general, they work in concentrated geographical areas and cooperate in larger innovation systems at the regional, national, and global levels [3]. According to other scientists, clusters should be based on the innovative technologies development, while enterprises involved in the cluster integration form are interested in innovative technologies [4, 5], pointing out that it is due to their innovative component that enterprises of the cluster are able to produce unique products. This, in turn, provides an opportunity to create their own unique market niche of the highdemand product. Although the external interactions are considered as important for the development and maintenance of cluster innovations, only a few studies identified the unique and ever-shifting aspects which are established between elements [6]. Scientific economic studies define "cluster" grouping forms, usually structured by employment segments, in which companies from the same market sector participate. The cluster type of interaction includes something like collective projects work intended to support competitive abilities of the regional industry. Collective goals become key and more important in a cluster than personal interests. Clusters become a source of positive externalities. The author of this "industrial regions" concept is A. Marshall [7].

In the Russian Federation, the very notion of building the architecture of cluster technology and process of cluster paradigm was developed a short time ago, hence, the lack of research of the "cluster" definition in the region economy agricultural sector determines the topicality of the problem discussed in this paper.

According to M. Porter's cluster theory of economic development, a cluster is a group of geographically adjacent integrated companies and associated organizations which operate in the specific area and complement each other. In the context of knowledge-driven economy operation, Morrison and Rabellotti [8] point out that clusters and local production systems, informal relationships become the key channel in industrial "regions". Agrarian cluster can be considered as a territorially detached innovative integrated association based on agricultural production and including various agricultural areas, which form the technological chain of the final product fabrication with elements of network organization. It is also worth to mention that cluster generation process is developing due to the cooperation of large companies with medium and small businesses within the scope of outsourcing and subcontracting. This is achieved thanks to the fact that large companies exclude many business processes from the production chain and transfer them to smallscale ones that gives them an opportunity to focus on the main business activity along with streamlining the organizational structure and reducing the costs. At another point, small and medium-sized businesses, provided with orders from large businesses, gain long-term cooperation with large enterprises. This case makes it possible for them to reduce entrepreneurial risks and costs, increasing the volume of goods or services and, consequently, minimizing fixed charges per unit. The role of a large enterprise as a key player in the cluster integration model is crucial, especially at the early stage of cluster development [9].

The studies of different scientists focus on the fact that agriculture, as a supplier of raw materials for food production, and the processing industry, which provides food consumption, are the warrants of the country's security being the basic sectors of sustained development [10]. Agrarian business management should be implemented taking into account business environment changes. That is why the region cluster environment in the agro-industrial complex economy is a structural element of the entire state industry 
sustainable development.

The analysis of different scientific works allows for the conclusion that the modern economy selects for the powerful innovation clusters generation in search of unique operation advantages $[11,12,13,14]$. These days many countries use the cluster approach to deal with micro-and mesoeconomic processes. The top priority of the current economic policy is the national innovation system development with due regard for the cluster nature of competitive industries. Agrarian business management should be considered taking into account the conditions of uncertainty of agriculture operation, the impact of negative processes on the functions and structure of national regulatory bodies of business function, which require further research and deepening of conceptual questions of the managed socio-economic development of agriculture, buildup of cross functional theoretical concepts for management systems organization [15].

According to the authors, within the current market reality for the purpose of agricultural enterprises successful operation, special attention should be paid to the generation and development of RCE as a key direction of territory's economy strategic growth.

As can be seen from the above, the RCE should be considered as an integrated form of associated agricultural companies or a group of agro-industrial enterprises located on a territory with the appropriate geographical distance, connected by interdependent channels of all types of communications by means of information technologies under the conditions of digitalization, representing a united resource complex that operates to accomplish common strategic tasks.

\section{Results}

For the regional economy, cluster policy in agriculture is the ground for innovation encouragement, technologies commercialization developing, direct investment raising, competitiveness and agrarian business products quality improving, as well as improving the quality of management in agricultural cluster organizations. The relevance of the buildup of innovation cluster development strategic plan for the Rostov region is resulting from, first, the presence in the region of the high total share of the structurally depressed industries, especially in the agricultural sector, and, second, a high density of the extensive agricultural production in the region sectoral structure.

In the Rostov region there is a number of large agricultural enterprises which products are competitive in the domestic and foreign markets, and on the basis of which clusters can be generated in the framework of vertically integrated companies in the agro-industrial complex, in accordance with the concept of the Rostov region cluster development for 2015-2020 and the strategy of the Rostov region socio-economic development for the period up to 2030 (Table 2).

Table 2. The largest agricultural enterprises of the Rostov region (at the date 31.12.2018).

\begin{tabular}{|l|c|c|c|c|c|c|}
\hline \multirow{2}{*}{$\begin{array}{c}\text { The largest agricultural } \\
\text { enterprises of the Rostov } \\
\text { region }\end{array}$} & \multirow{2}{*}{$\begin{array}{c}\text { Foundation } \\
\text { year }\end{array}$} & \multicolumn{5}{|c|}{$\begin{array}{c}\text { Operating revenue, millions of rubles } \\
\text { (at effective prices) }\end{array}$} \\
\cline { 3 - 8 } & & $\mathbf{2 0 1 4}$ & $\mathbf{2 0 1 5}$ & $\mathbf{2 0 1 6}$ & $\mathbf{2 0 1 7}$ & $\mathbf{2 0 1 8}$ \\
\hline 1 & 2 & 3 & 4 & 5 & 6 & 7 \\
\hline Corporate group "Evrodon" & 2003 & 4159 & 4750 & 5270 & 8268 & 5714 \\
\hline Agro-industrial holding "Aston" & 1997 & 19468 & 18679 & 25889 & 28911 & 37413 \\
\hline ZAO "Yug Rusi" & 1992 & 5063 & 6075 & 9055 & 11644 & 5379 \\
\hline OOO "Agrofirma "Tselina" & 2004 & 1383 & 1558 & 1572 & 2144 & 1992 \\
\hline $\begin{array}{l}\text { OOO "Russkaya svinina" } \\
\text { (ZAO "Russkaya svinina" - } \\
\text { predecessor) }\end{array}$ & 2005 & 946 & 1002 & 923 & 1228 & 1449 \\
\hline
\end{tabular}




\begin{tabular}{|l|c|c|c|c|c|c|}
\hline $\begin{array}{l}\text { OAO "Ptitzefabrika } \\
\text { Taganrogskaya" }\end{array}$ & 2001 & 1005 & 1451 & 1396 & 1289 & 1554 \\
\hline $\begin{array}{l}\text { OOO "Semikarakorskiy } \\
\text { syrodelnyiy kombinat" (OAO } \\
\text { syrodelnyiy zavod } \\
\text { "Semikarakorskiy" - predecessor) }\end{array}$ & 1969 & 2170 & 2480 & 3142 & 3044 & 3092 \\
\hline OOO "Amilko" & 2006 & 2530 & 3083 & 3589 & 3727 & 4521 \\
\hline OOO KF "Mishkino" & 2011 & 296 & 1070 & 1235 & 1080 & 944 \\
\hline $\begin{array}{l}\text { OOO “Azovskaya konditerskaya } \\
\text { fabrika" }\end{array}$ & 2008 & 3528 & 4748 & 6538 & 6854 & 6472 \\
\hline OOO "Beliy medved" & 1997 & 1323 & 549 & 560 & 452 & 502 \\
\hline OOO "Donstar" & 2010 & 1494 & 2611 & 3355 & 2930 & 2126 \\
\hline
\end{tabular}

The necessary scientific, educational and innovative potential for implementation of the technical component of cluster projects in the process of their development (engineers, designers, programmers) in the field of such key areas as: environmental safety, biotechnologies, technologies of living systems, information and telecommunication technologies, is provided by the following research and educational organizations of the Rostov region: FSBSI "ANTS "Donskoy", FSBSI FRANTS, Russian research and development centre of land-clearing problems, Russian national research and development centre of meat industry named after V. M. Gorbatov, North Caucasian zonal research and development veterinary centre, South Federal University, Don State Technical University, Rostov State University of Economics, Don State Agrarian University and others.

The infrastructure base for generation and development of RCE in the Rostov region is presented by the engineering, energy, transport, production and social infrastructure together with the high investment attractiveness of the region.

In addition, the don region has a developed network of innovative infrastructure. The Center for cluster development of the Rostov region efficiently operates for the purpose of rendering state assistance for clusters potential development. The center was established with the support of the Rostov region government on the basis of the ANO "RRAPP" (autonomous non-for-profit organization "Rostov regional agency of business support") (Figure 2). 


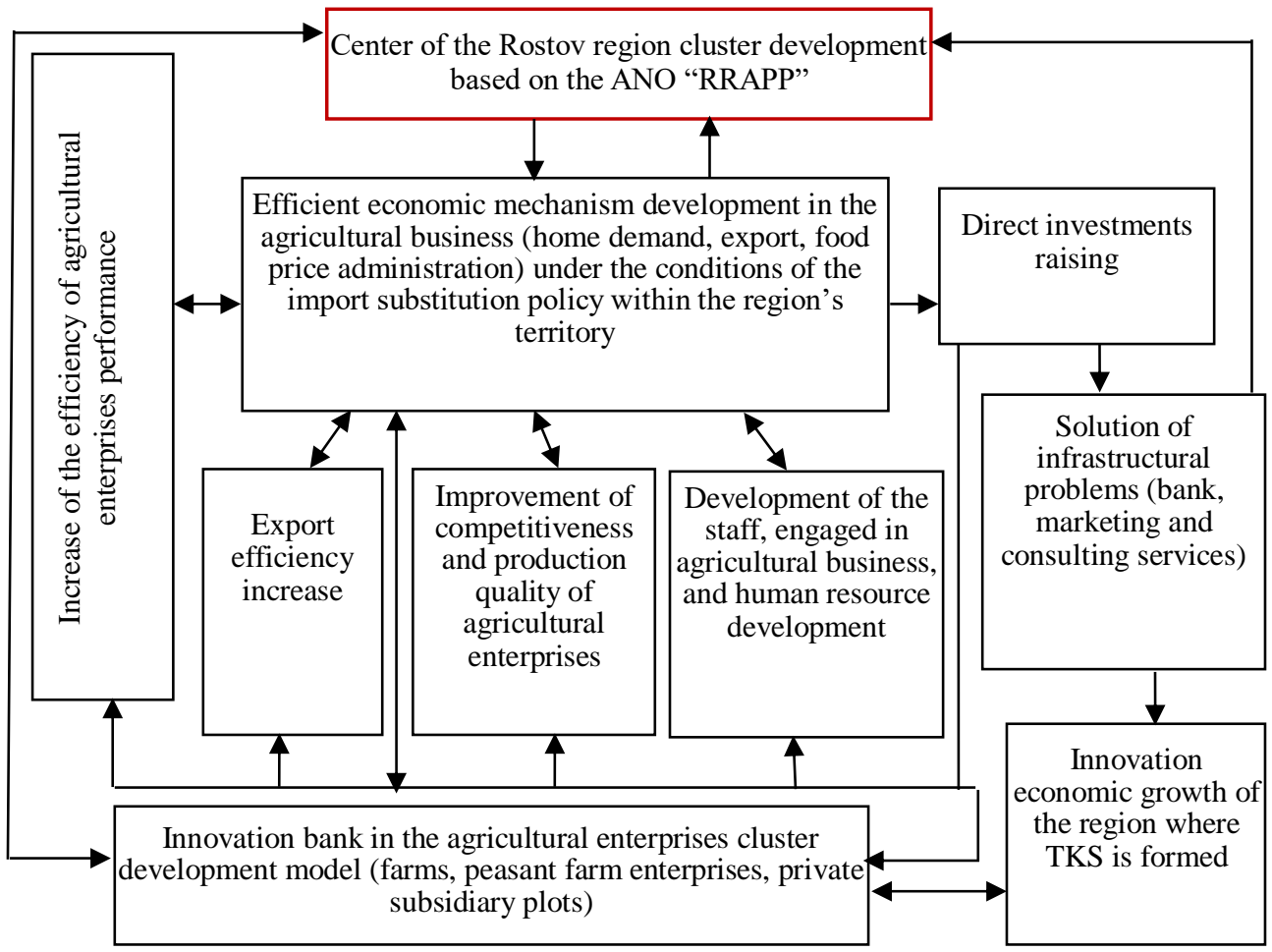

Fig. 2. Region cluster environment management model in the agro-industrial complex (exemplified by the Rostov region).

In line with the Concept of the Rostov region cluster development, eight clusters and two cluster initiatives are developed in the region and included on the register approved by the Governor. Furthermore, in accordance with the government regulation of the Rostov region, a number of development strategies for 2016-2020 are developed in the agroindustrial complex for such top-priority territorial clusters as:

1. Biocluster, the purpose of which is advanced grain processing, production of highprotein feed and starch products in order to saturate not only regional but also national market, as well as to solve import substitution problems with the start-up projects of OOO "Donbiotech" and OOO "Amilko".

2. Innovative territorial cluster "Donskie molochnyie produkty", intended both to achieve the solution to the dairy products import substitution problem, and to assemble the scientific, technical and production potential of enterprises of this cluster sectoral focus.

3. Territorial cluster "Dolina Dona" created for the development and production of viticultural and wine products for the purpose of active growth of the Rostov region wine trade, export promotion and marketing development in the national market, in part for import substitution of foreign products in the given segment of the product niche along with increase of the Russian and foreign investments inflow and improvement of production and region competitiveness.

4. National industrial cluster of agricultural engineering is of great importance for the technical support of performance and continuous development of the Don agricultural production, which framework is formed by such enterprises as OOO "KZ "Rostselmash", AO "Klever", OAO "Millerovoselmash", OOO "Salskselmash", OAO "Kormmash".

In addition, in accordance with the Strategy of the Rostov region socio-economic development for the period up to 2030, two more clusters should be generated: the meat 
cluster, covering a number of bred livestock farms, meat factories and feedlots in the northand southeastern parts of the Rostov region, and the cluster of the poultry meat and eggs production, saturating the regional and national market and accessing in the long run the foreign markets of the Middle East, Asian markets, African markets, CIS, etc.

\section{Conclusion}

The opportunity of expanding of prosperous functioning conditions of small and medium enterprises and raising of direct investments, development of educational operations, transport, energy and other infrastructure, and agricultural products exports should be considered as one of the growth poles and competitive advantages of the Rostov region in case of the introduction of Region innovative cluster model of agro-industrial complex development management in comparison with the individual form. In view of this, the generation of territorial effects and cluster model of the region development management, mutually integrating the resources and capabilities, in the feedback mode makes it possible to increase the agricultural enterprises competitiveness and innovation abilities of the territory upon the whole.

In the course of investigations it is found that at present for successful operation and development of innovation clusters in agro-industrial complex of the Rostov region the strategic aim should be determined in the form of the need to implement more specific policy in the field of agricultural production, adjusting it to particular problems, integrating structural and product policies of the agricultural sector in order to build the region cluster environment management system that would be efficient and relevant for the current unsteady market conditions.

It is necessary to further investigate the issues of RCE improvement, to assess all participants of the clustering process in order to achieve more efficient control of the territory agro-industrial economy growth, as the most promising and key direction.

\section{References}

1. Y. Ragulina, E. Stroiteleva, A. Miller, Modern Applied Science 9(3), 145 (2015)

2. Mário M. Franco, L. Esteves, Journal of Innovation \& Knowledge 5, 39 (2020)

3. L. Kay, J. Youtie, P. Shapira, Knowledge Management Research \& Practice 14(3), 280 (2016) doi.org/10.1057/kmrp.2014.30

4. S. Avdasheva, Household Connections in the Russian Industry: Pro Challenges and Trends of the Last Decade (HSE, Moscow, 2000)

5. M. Kunelbayev, O. Auyelbekov, N. Katayev, D. Silnov, International Journal of Applied Engineering Research 11(6), 4066 (2016)

6. J.S. Engel, I. del-Palacio, California Management Review 53(2), 27 (2011)

7. E. Montaigne, A. Coelho, Wine Economics and Policy 1(1), 41 (2012)

8. A. Morrison, R. Rabellotti, European Planning Studies 17(7), 983 (2009) doi:10.1080/09654310902949265

9. M. Gureva, S. Lyubimtseva, T. Tukhkanen, O. Lyubimtseva, L. Simonova, E. Kolpak, International Journal of Economics and Financial Issues 6(S8), 115 (2016)

10. G. Grigoreva, M. Kabanenko, N. Andreeva, IOP Conf. Series: Earth and Environmental Science 274, 012074 (2019) doi:10.1088/1755-1315/274/1/012074

11. V. Mazur, K. Barmuta, S. Demin, E. Tikhomirov, M. Bykovskiy, International Journal of Economics and Financial Issues 6 (1S), 270 (2016) 
12. A. Babkin, A. Novikov, Scientific and technical statements STU Economics 235(1), 9 (2016)

13. L. Gitelman, Y. Magaril, M. Khodorovsky, Economy of Region 19, 174 (2014)

14. L. Tkachuk, A. Korzh, G. Korotkova, European Coatings. 221(3), 52 (2015)

15. A. Chernaya, M. Kabanenko, S. Ugrimova, Conf. Series: Earth and Environmental Science 274, 012073 (2019) doi:10.1088/1755-1315/274/1/012073 